\title{
Towards a Pattern Language for the Masters Student
}

\author{
Hugo Sereno Ferreira \\ hugo.sereno@fe.up.pt \\ University of Porto, Faculty of \\ Engineering \\ Department of Informatics \\ Engineering \\ and
}

Instituto de Engenharia de Sistemas e

Computadores - Tecnologia e Ciência

(INESC-TEC)

Porto, Portugal

\author{
André Restivo \\ arestivo@fe.up.pt \\ University of Porto, Faculty of \\ Engineering \\ Department of Informatics \\ Engineering \\ and \\ Artificial Intelligence and Computer \\ Science Laboratory (LIACC) \\ Porto, Portugal
}

\author{
Tiago Boldt Sousa \\ tbs@fe.up.pt \\ University of Porto, Faculty of \\ Engineering \\ Department of Informatics \\ Engineering \\ Porto, Portugal
}

\begin{abstract}
Every year, thousands of new students begin their Masters in STEMrelated topics. Despite being regarded as a common occurrence by the faculty, it represents the culmination of years of studying and preparation for their professional life. Notwithstanding, these students face well-known recurrent problems: how to choose a topic, how to choose an advisor, how to start researching, and how to deal with all the unknowns associated with academic research. Although there are several books on how to write a thesis, most of them avoid prescriptive recommendations on topics beyond research per se or focus on doctoral students, for which the duration and motivation are significantly different. In this paper, we draft a pattern language comprised of thirty patterns that we have observed from supervising over a hundred masters students within the last decade.
\end{abstract}

\section{CCS CONCEPTS}

- Applied computing $\rightarrow$ Education; • Software and its engineering $\rightarrow$ Design patterns.

\section{KEYWORDS}

Educational Patterns, Masters, Students, Dissertation

\section{ACM Reference Format:}

Hugo Sereno Ferreira, André Restivo, and Tiago Boldt Sousa. 2019. Towards a Pattern Language for the Masters Student. In 24th European Conference on Pattern Languages of Programs (EuroPLoP '19), July 3-7, 2019, Irsee, Germany. ACM, New York, NY, USA, 12 pages. https://doi.org/10.1145/3361149.3361184

\section{INTRODUCTION}

Across all continents, an unprecedented amount of new students are undergoing their master's dissertation in science, technology, engineering, and mathematics-related topics. Despite being regarded as a common (in the sense of usual) occurrence by the faculty, it is a

Permission to make digital or hard copies of all or part of this work for personal or classroom use is granted without fee provided that copies are not made or distributed for profit or commercial advantage and that copies bear this notice and the full citation on the first page. Copyrights for components of this work owned by others than ACM must be honored. Abstracting with credit is permitted. To copy otherwise, or republish, to post on servers or to redistribute to lists, requires prior specific permission and/or a fee. Request permissions from permissions@acm.org.

EuroPLoP '19, fuly 3-7, 2019, Irsee, Germany

(c) 2019 Association for Computing Machinery.

ACM ISBN 978-1-4503-6206-1/19/07 ..\$15.00

https://doi.org/10.1145/3361149.3361184 singular event in the life of a student, representing the culmination of years of studying and preparation.

Every year new students face the same doubts over and over again: "how do I choose a topic?", "should I choose something that I like or something that will boost my career?", "which professor(s) should be my advisor(s)?", "what is this thing called research?", "how am I supposed to come up with something novel?", "am I performing differently from my colleagues?", and so on.

From their point of view, there are a plethora of unknown unknowns associated with this (typically brief) contact with academic research. The experience per se should not be overlooked. The professors that will be performing supervision duties are known to be undergoing their problems too, under an increasingly competitive and stressful environment [3]. The challenges of this "academic mindset" ultimately trickle down to students; not even the most brilliant of them are immune to self-delusion at both ends of the spectrum: the Imposter Syndrome [5, 6], where students consider themselves incapable of performing a task, and the Dunning-Kruger effect [9], a cognitive bias that leads students to believe they are more competent than they actually are.

Notwithstanding the availability of several books on how to write a thesis [8, 12], most of them either (a) avoid giving recommendations on things beyond research per se, or (b) are mostly focused on doctoral students, for whom the time-span and motivation are significantly different. Some of these questions are philosophical, and we very much doubt there is a definitive, objective answer that does not turn out to be opinionated. When discussing these patterns with our colleagues, we can immediately conclude that most tend to concur easily with the identified problems, but quickly diverge in their prescriptive solutions.

We claim that both the academic machinery and human psychology evidence behavioral patterns that are highly correlated with the success of producing and defending a master's thesis. It is outof-scope of this work to provide empirical evidence that such is the case, however. Ergo, we base the "best-practices" herein captured on both our personal experience as well as existing literature... for the time being.

In this paper, we draft a pattern language comprised of thirty patterns that we have personally observed from over a hundred candidates whom we had supervised during our professorship, 
taking significant inspiration from the work of Joseph Bergin's patterns for doctoral students [4].

When we refer to a thesis, we are referring to the "long essay or dissertation involving personal research, written by a candidate for a university degree," as described by the Oxford Dictionary, sometimes also referred as merely a dissertation.

\subsection{Target Audience}

Our target audience is students that need to write a dissertation (usually summing up a project) as partial fulfillment of the requirements for the degree of Masters in Science (M.Sc.). This does not mean that the prospective reader must be a student, though; we believe advisors - new and veteran alike - would equally benefit from reading this work, if not for the sole reason of providing insight into the students' process, as well as potentially serving as a conduit to pass these prescriptions unto the unaware pupil. While most of these patterns are applicable to students undergoing any research program, our focus reflects our expertise and addresses Computer Science and Engineering Master's degrees.

\subsection{Methodology}

This work is the result of our accumulated empirical knowledge, resulting from the supervision of over 100 Master theses, and over 150 participations as thesis committee members.

\subsection{General Forces}

The objective of the typical M.Sc. student is not only to successfully finish their dissertation but also to do it with a grade that will satisfy their ambitions ${ }^{1}$. We identify three general forces affecting the final grade of their work, c.f. Figure 1. Each pattern is governed by its specific forces, which in turn have an impact on the resolution of these more general ones:

- QUALITY. Not the quality of the student, but of the work the student performs during the whole process, leading to the quality of the final work;

- Complexity. Not all dissertations are equal; each one has an inherent complexity that greatly influences, and sometimes sets an upper bound, on the student's grade;

- TIME. The time a student dedicates to their thesis, this force has a maximum bound, equal for all students, defined by the program where they are enrolled.

- GRADE. The final grade attained by the student from their thesis defense; this force is a product of how the other forces are balanced and cannot be directly controlled by the student

One can establish some invariants governing the dynamics of these forces: (1) the more COMPLEXITY a thesis has, the more TIME a student must dedicate to it and the more QUALITY the work needs to evidence; (2) if a student does not dedicate enough TIME to their thesis, its QUALITY will decline unless the COMPLEXITY also falls; and (3) the more QUALITY in a student's work, the more COMPLEXITY their thesis can have without the need for more TIME.

Student experience is a candidate force, which we are currently assessing and considering to include as a force in future versions

\footnotetext{
${ }^{1}$ Proudness and a sense of accomplishment are among the driving forces. However, for those that intend to pursue a doctorate, later on, the grade can be a defining parameter in the award of a scholarship.
}

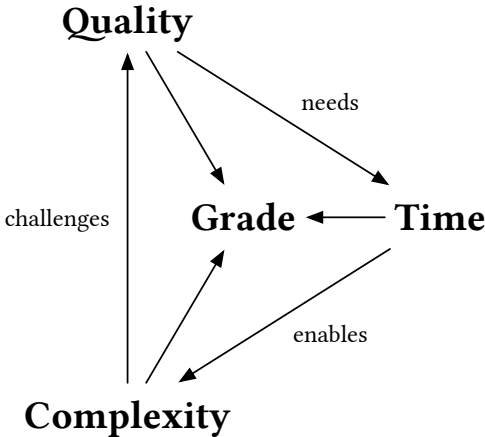

Figure 1: General forces governing the student's GRADE and their relations. We can see that COMPLEXITY challenges QUALITY, as it is troublesome to maintain quality with an high complexity research. QUALITY itself requires TIME, while TIME enables COMPLEXITY. The three external forces influence the final GRADE.

of this research. There might also exist secondary forces that are contingent on differences between universities, courses, and even research topics. Some of these include, but are not limited to: (i) research relevance, (ii) originality, and (iii) scientific methodology.

\subsection{How to read these patterns}

We divide the patterns into four different temporal phases:

(๑) Prepare. For when the student has not begun their M.Sc. work but is on the verge of deciding what area to pursue, and with which advisor. Patterns in this category are: SINE QUA NON (1), POISONED SALARY (2), TOPIC PASSION (3), SELF-SUFFICIENT RESEARCH (4), COMPATIBLE ADVISOR (5), INFORMED ADVISOR (6), and ADVISOR'S ADVICE (7);

(O) Bootstrap. For the early stages of the dissertation, when students are already committed to an area and advisor, but still trying to narrow down their hypothesis. Patterns in this category are: BEATEN TRACK (8), CURIOUS MINDS (9), LANTERN TO LASER (10), SHOULDERS OF GIANTS (11), SOLVABLE PROBLEM (12), ELEVATOR PITCH (13), SAFETY NET (14), BIG PICTURE (15), and DISSERTATION OWNERSHIP (16);

(O) Research. For the main part of the dissertation, the one where the bulk of the work is done, and perseverance takes the central role. Patterns in this category are: POINT OF NO RETURN (17), UNCOMPLICATED LIFE (18), WOLF PACK (19), SUSTAINED EFFORT (20), BOOKWORM (21), NOT ABOUT THE CODE (22), and RESUlTS ARE RESULTS (23);

(๑) Deliver. When the research is in its final stage, and the student is just closing things up, making sure that the final document is representative of all the hard work done during the dissertation. Patterns in this category are: SELF-CRITIC (24), REWRITE LOOP (25), SELFREADER (26), SAFE HOUSE (27), LASTING RESULTS (28), NO TELEPATHY ALLOWED (29), and FORWARD-LOOKING (30). 
The exact chronological length of these phases varies between different institutions, but for a typical one-year dissertation, one should expect a time ratio of 1:3:6:2 for the four phases. Ideally, the last two phases would proceed mostly intertwined. A general overview of the interconnection between these patterns can be observed in Figure 2.

\section{A PATTERN LANGUAGE}

Throughout the following sections we present a condensed version of the patterns, in the form of patlets, for the four main phases: Prepare, Bootstrap, Research and Deliver, as described above. Each pattern contains the problem statement, the prescriptive solution, and a rationale that conveys the way it balances the underlying forces.

\subsection{Sine Qua Non (๑)}

You are just beginning your dissertation, and you have almost no knowledge of its process. Some of the requirements of a dissertation are rigid (like deadlines), but some differ and evolve (like the scope). Most of the requirements are set by others, not you. The institution and course set some, your advisor will set others. Some of your colleagues may have already talked a bit about the BEATEN TRACK (8), but, in any case, you are ultimately responsible for your actions, and you need to decide how to start and what your goals are.

Therefore, learn the requirements set by your institution. Understand the goals and deadlines. Your program's director and advisor can help you with finding those. Do not underestimate the bureaucracy, as it is probably the most rigid of them all. The more you know beforehand, the better you can plan for the worst.

Rationale: Almost in every case, the student has a TIME requirement that varies between six months to a year for most programs. A successful delivery also implies that the work needs to meet a certain COMPLEXITY level, sometimes with external indicators such as publications in conferences or journals. And the QUALITY of the work needs to meet a certain standard, notwithstanding the advisor's expectations. Also see: ADVISOR's ADVICE (7), SAFETY NET (14), POINT OF NO RETURN (17).

\subsection{Poisoned Salary (๑)}

Some students prioritize finding a project that provides a research grant or salary. In fact, this might be the first opportunity you are offered to start earning some money and feel (more) independent from your parents. Or you are already in a company or institution and want to keep your work during this phase. You might even be tempted to prioritize companies or laboratories that propose a salary or grant. Your dissertation might be part of their mission. However, sometimes, their priority is in recruiting or having a temporary workforce, disregarding your academic interests.

Therefore, be aware that money is a two-edged sword. Consider that a company or laboratory has its own interests, which might supersede yours in completing the dissertation with a high grade. Once money gets in the way, you have a contractual - and psychological - obligation to the entity. You should consider it very carefully when accepting it to avoid a conflict of interest in the future. Your INFORMED ADVISOR (6) and older colleagues have already taken the BEATEN TRACK (8). They can share valuable experience about a specific company or laboratory.

Rationale: The interests of the company or lab might go against TIME - and sometimes even COMPLEXITY - requirements, or expectations. In the case of companies, the institutional advisor may be able to shield the student from such situations without breach of contract. Intellectual property is often a pressing issue when aiming for LASTING RESULTS (28). When it comes to research labs, it is a more delicate situation that might either benefit the student, c.f. WOLF PACK (19), SHOULDERS OF GIANTS (11), or put their personal ambitions at risk, c.f. DISSERTATION OWNERSHIP (16). Besides the impact of salaries and grants during this period, other external interests might also become a liability for the dissertation. So, even if the research project is not covered by a salary or grant, one should struggle to shield from external forces that might attempt to bias the work and distract the focus from the scientific goals. Also see: SELF-SUFFICIENT RESEARCH (4), FORWARD-LOOKING (30).

\subsection{Topic Passion (๑)}

You need to write a dissertation and are about to start an arduous path! Burnouts happen more often than people realize. It is something that will last a considerable period of time, and is best done $^{2}$ in exclusivity. Even if you have a working schedule, it will be challenging to get your mind out of your research. Moreover, if you undertake experimental work, things might not proceed as expected. Those who ultimately succeed best tend to be those who are compelled to endure despite all adversities.

Therefore, select a topic you have passion for. Your academic and, potentially, your professional experience, as well as your personal curiosity, will play an important role in understanding what topics you would like to work with. Don't be afraid to ask the faculty members and your colleagues about their research to guide this decision. This passion will be needed to carry you over hard times, to make you enjoy being a воокwоrм (21), to make you come back after failing, to give you strength for the REWRITE LOOP (25), to accept that RESULTS ARE RESULTS (23) nonetheless, and to awake your creative self.

Rationale: Enjoying the topic at hand, either directly because the student has a passion for it, or indirectly because it believes in the BIG PICTURE (15), will help them keep a SUSTAINED EFFORT (20), which will improve the QUALITY of the work, and make any TIME requirements more attainable. It is, ultimately, a psychological factor with a significant impact on the student's happiness and subsequent productivity, as well as in their ambitions for a higher GRADE. Also see: ELEVATOR PITCH (13), INFORMED ADVISOR (6), UNCOMPLICATED LIFE (18).

\subsection{Self-sufficient Research (0)}

You are undergoing your research, and you have become one of the curious MINDS (9). You've been drafting experiments in the

\footnotetext{
2 "Best done" is a misnomer, as some degrees and grants specifically require exclusivity.
} 


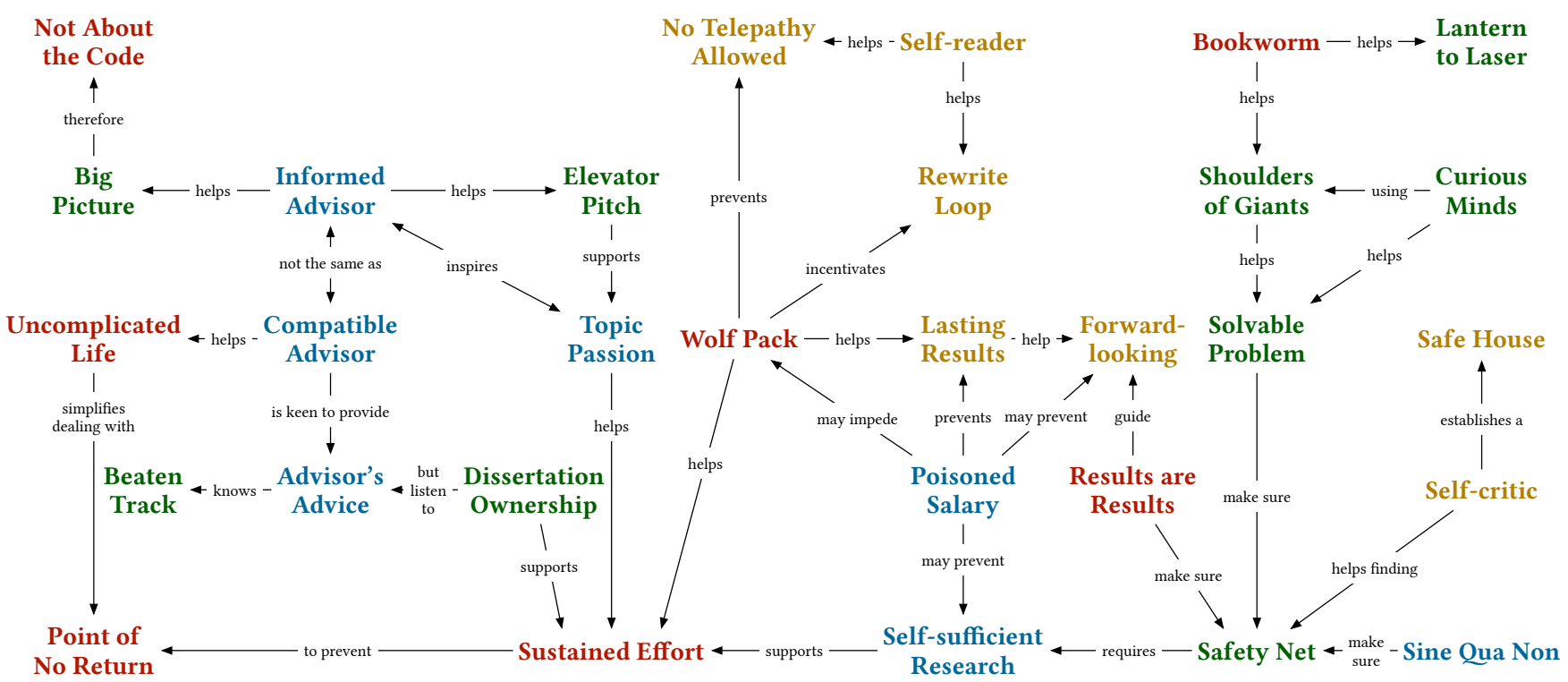

Figure 2: The patterns and their most relevant relationships. Different chronological phases are typeset in different colors, viz: (๑) Prepare, $(\odot)$ Bootstrap, $(\odot)$ Research, and $(\odot)$ Deliver. This figure is color-coded to facilitate visualizing the pattern's categories. Section 1.4 has a textual description of this same information.

search for a SOLVABLE PROBlem (12). You might have been developing some software too. Those experiments might depend on the usage of specific hardware, or licensed 3rd-party software, or even other colleagues' pending results or collaborations. Hardware and software tend to fail. People tend to underestimate the time needed to complete their work. Ultimately, all of this will probably be out of your control to fix.

Therefore, avoid external dependencies. Attempt to reduce your work to scenarios where you control most (if not all) the pre-requirements. Have a SAFETY NET (14) in case the software and hardware you are using fails. If possible, design your research so that you do not necessarily need the dependencies to succeed.

Rationale: By avoiding external dependencies, the student is less prone to break any TIME requirements and keep a SUSTAINED EFFORT (20). Project proponents (companies or laboratories) might also attempt to be FORWARD-LOOKING (30) by grounding their proposal on pending results. Still, unless they are promptly available in their final form, they might become a liability to the COMPLEXITY and the QUALITY of the final work. Also see: Poisoned SAlary (2).

\subsection{Compatible Advisor (๑)}

No two people are alike, which is true for both teachers and students. While this is probably your first dissertation, your advisor knows the BEATEN TRACK (8), as they have possibly already undertaken a few students before. Your personal goals may differ. Still, most students tend to be looking for a subset of the same needs: (a) good advice, (b) protection from institutional or company politics, and (c) someone who knows how to push and give you space appropriately, recognizing your DISSERTATION OWNERSHIP (16). This is the very definition of a mentor, if not of a friend.

Therefore, find an advisor with whom you can work comfortably and who will help you achieve your goals. Typically, a professor with whom you have enjoyed working in previous courses. Be aware, though, that this might not be the same as an INFORMED ADVISOR (6), or one that will give you the best ADVISOR's ADVICE (7). Ideally, you want the three traits to be present, but we are but humans, after all.

Rationale: The student should not only pursue an UNCOMPLICATED LIFE (18) but also make sure this extends to the relationship and synchronicity with the advisor, as they are the ones knowledgeable of the BEATEN TRACK (8). This helps keeping expectations in check on both sides concerning COMPLEXITY and GRADE. A compatible advisor might balance someone who is not an INFORMED ADVISOR (6) when the student is skillful regarding the research topic. Likewise, if the student exhibits a high degree of initiative, and understands the advantages of being part of a WOLF PACK (19), it might help when having someone who doesn't always give the best ADVISOR'S ADVICE (7).

\subsection{Informed Advisor (0)}

Sometimes you enjoy a particular professor, either because of their style or exhibited knowledge. So you consider them to be a сомPATIBLE ADVISOR (5). You might also feel that you have a lot to learn before being able to see the BIG PICTURE (15), and you like the way this professor teaches. But professors have their own research topics and are usually very busy. Bootstrapping knowledge in a specific topic takes a considerable amount of effort, reading, and guidance to stand on the SHOULDERS OF GIANTS (11). Even if you 
invite them to be your advisor, there might be a chance they decline: not necessarily because they don't like you, but because they might not be comfortable with the topic.

Therefore, find an advisor that is an expert on your research topic and works in that same research area, as it will ease your journey. The fact that both of you share the same TOPIC PASsion (3) will also help in keeping your INFORMED ADVISOR (6) interested in your progress.

Rationale: Academics tend to self-organize in highly-specialized research groups. This might be regarded as a consequence of the highly competitive society in which they develop their work. An INFORMED ADVISOR (6) tends to have strong connections with these groups, with all the associated benefits: (a) it helps the student become part of a WOLF PACK (19), (b) it eases the path to stand in the SHOULDERS OF GIANTS (11), (c) it facilitates the financial and technical support needed to achieve LASTING RESULTS (28) and SELFSUFFICIENT RESEARCH (4), (d) there is probably a ready-available SOLVABLE PROBLEM (12) to be tackled, and (e) being FORWARDLOOKING (30) is part of their job. Notwithstanding, the expectations on QUALITY and COMPLEXITY of an informed advisor are understandably higher, so caveat emptor. Also see: BEATEN TRACK (8).

\subsection{Advisor's Advice (๑)}

Your advisor may have specific ideas about what you should do, particularly if they are the project's proponent or an INFORMED ADVISOR (6). These may differ from your own ideas, as you are attempting to have the DISSERTATION OWNERSHIP (16). In any case, they will have the last say in deciding when you are finished and how successfully you were.

Therefore, listen to the advice of your advisor when they are willing to give it to you. Understand there is a BEATEN TRACK (8) that they know of, and that they may pass unto you. And do not tend to disagree too much with them ${ }^{3}$. You should pursue DISSERTATION OWNERSHIP (16); still your advisor may have something valuable to contribute, as they are probably already standing on the SHOULDERS OF GIANTS (11).

Rationale: The goal of having an advisor is precisely to be advised. An INFORMED ADVISOR (6) may be knowledgeable in the topic, but just not have the time or interest to keep up with the student's work A COMPATIBLE ADVISOR (5) may share so many of the interests with the student that it relaxes the appropriate demands of COMPLEXITY required to attain a higher GRADE. But both of them will have a saying in the final classification. Once the student has committed to an advisor, the best course of action is to actually listen.

\subsection{Beaten Track (o)}

You achieved a balance between someone that can give you a good ADVISOR'S ADVICE (7), an INFORMED ADVISOR (6), and a COMPATIBLE ADVISOR (5). You have got yourself acquainted with the dissertation

\footnotetext{
${ }^{3}$ What is too much? Constructive disagreement is useful, and the subsequent brainstorm usually pays off. Refusing to write a particular chapter, to investigate one specific approach, or to increase the complexity level because you think it is already "enough", might sound more like stubbornness, and put you in a very delicate position.
}

process and know all the SINE QUA NON (1). Still, this is probably the first dissertation you have ever written. You might feel a bit lost without knowing precisely what you should expect and what should be your next steps.

Therefore, get yourself acquainted with how others have tackled their dissertation in the past. In particular, your advisor was a student once too, and in all likelihood, went through the same challenges and struggles you are currently experiencing. If they are experienced, they have probably already undertaken a few students before. Besides, you are not the first (and neither the last) person to have ever written a dissertation. As you read this, realize most of your older colleagues have gone through the same experience. If you do not intend to be left out of a WOLF PACK (19), you will probably share the same office or laboratory with them. Likewise, do not attempt to game the process with your advisor; they know all the tricks, and you will probably just end up losing your ADVISOR's ADVICE (7).

Rationale: Students face the same doubts over and over again. Some institutions try to prepare them through some courses on introductory research or dissertation preparation. But from the student's point of view, there are a plethora of unknown unknowns associated with the discovery of academic research. Even the most brilliant of them are not immune to the Imposter Syndrome [5, 6]. So they must understand that, while this is all very new to them, it is a common, well-known path. Once most of the unknowns are enlightened, the student is able to dedicate more TIME and becomes less afraid of increasing the COMPLEXITY of their work, ultimately leading to an higher work QUALITY and GRADE. Also see: SHOULDERS OF GIANTS (11).

\subsection{Curious Minds (๑)}

The goal of a dissertation is to answer some essential unanswered question, not to do the job that people already know how to do. If there is no question to be asked, there is no answer to be found. Questions are everywhere: there is more that is unknown than what is known, and to know, one must stand on the SHOULDERs of GIANTs (11). Being a BOOKWorm (21) will make you realize that every paper you read, every book you study, will leave questions unanswered, either implicitly or explicitly.

Therefore, invest some time in coming up with your own relevant research questions. Do not assume as axiomatic truth what others say just because they seem knowledgeable ${ }^{4}$, although it helps when it comes from an INFORMED ADVISOR (6). Write these questions in a notebook, with the appropriate reference to the paper or book where you have read them, as they will become invaluable resources for your dissertation's motivation and related work. Discuss those questions with your advisor. Be bold... but do not forget that you must stick to a SOLVABLE PROBLEM (12).

Rationale: Without a research statement, usually in the form of a hypothesis, the QUALITY and GRADE of the dissertation are severely limited. This can be a serious liability when a POISONED

\footnotetext{
${ }^{4}$ Also known as argumentum ab auctoritate.
} 
SALARY (2) comes along and suddenly not everyone agrees that it is NOT ABOUT THE CODE (22). An INFORMED ADVISOR (6) may already be part of a research group, which would help immensely in finding a SOLVABLE PROBLEM (12). Still, the student must be the one to have the DISSERTATION OWNERSHIP (16), and it is only by asking (a lot) of questions that they will begin to understand the BIG PICTURE (15) and pursue an ElEVATOR PITCH (13). Also see: LANTERN TO LASER (10).

\subsection{Lantern to Laser (๑)}

You are being а воокwоRм (21) and reading a lot about your topic. You feel overwhelmed by the amount of knowledge out there, and the more you read, the more you are compelled to know how your topic relates to the rest of its field and to other human knowledge, like a lantern. You are feeling one of the CURIOUS MINDS (9), but are struggling to stand on the SHOULDERS OF GIANTS (11) and find a SOLVABLE PROBLEM (12). You start to feel - and you might have already had a similar ADVISOR's ADVICE (7) - that you need to focus, just like a laser. But you need a variety of perspectives to succeed.

Therefore, start as a lantern but eventually become a laser. Read for both depth and breadth initially, and do not shy away from things that are not exactly like yours. This is required for you to understand the BIG PICTURE (15) and is a crucial part of attaining a good ELEVATOR PITCH (13). The trick, of course, is in the balance: be nothing more than a lantern and you could spend your entire life reading; decide to be a laser too early in the process, and your aim might be entirely off, where you throw out probably already suitable solutions that could have been mapped to your needs. Still, you eventually need to become a laser and focus on your problem. Keep in check your POINT OF NO RETURN (17) so you can ensure a SUSTAINED EFFORT (20).

Rationale: Sometimes the student is just focused on doing the job someone asked them to do, particularly if they still have low DISSERTATION OWNERSHIP (16). Even if the task is of a high COMPLEXITY, it does not mean that there are no concepts and techniques in nearby fields that could not be easily mapped unto the task at hand. Focusing like a laser would just ignore the immense knowledge that could be reused. If the evaluating committee realizes this, the GRADE can be penalized, despite all the student's efforts. Nonetheless, the dissertation process is TIME-boxed, so one must eventually decide for a SOLVABLE PROBLEM (12), and the sensibility of an INFORMED ADVISOR (6) here is crucial. Also see: BIG PICTURE (15).

\subsection{Shoulders of Giants ( $(\bullet)$}

You want your thesis to be original. But all knowledge is based on prior knowledge [11]. And you are just one among billions of humans, living in a society where scientific literature - both good and bad - is exploding exponentially. Do not presume that no one has ever had your idea, that no one has tried to solve your solvable PROBlem (12), or that no one failed in the exact same quest. The absence of evidence is not evidence of absence.

Therefore, stand on the shoulders of giants, by building your research on top of the great work from previous researchers.
Do, or search for, a deep (possibly systematic) literature review, both to find what has worked - and not worked - for others, as to find evidence supporting both your thesis and its relevance.

Rationale: Sometimes what first seemed like a good idea has already been thoroughly studied by someone else. So students should not throw themselves at a problem without first researching it, or they will risk finding out that their work is not really that innovative too late in the game, and end up losing a lot of precious TIME. A significant amount of editors and researchers favor successes over failures $^{5}$, and disregard the fact that RESULTS ARE RESULTS (23), so it might not be easy to find information about some particular path that was already tried and failed. To get a good GRADE, the work should also have a high degree of COMPLEXITy, and for that to be true, without the QUALITY of the work suffering, claims should provide proper scientific evidence, or references to the literature must be included saving a lot of TIME. Also see: curIOUS MINDS (9), BOOKWORM (21), ELEVATOR PITCH (13).

\subsection{Solvable Problem (๑)}

You are about to begin your research, but there are too many open problems that you can address. Each can span to a level of complexity that might not be feasible when considering your program's restrictions at deadlines. You need a problem that is interesting to you, relevant to the scientific field, feasible in the available time frame, but not trivial.

Therefore, find a problem that is solvable within your program's restrictions. An INFORMED ADVISOR (6) can help you assess the complexity of your problem. You should probably try to first learn about the topic and related technologies to make an informed assessment. Do not attempt to solve every world's problem: it's an honorable pursuit, but a lifetime endeavor, not something to be expected in your graduation year.

Rationale: Strict deadlines often govern the life of a university degree. While a SUSTAINED EFFORT (20) can ensure continuous progress, some problems have too much complexity for the TIME imposed by the degree restrictions. Expectations should be realistic, and an INFORMED ADVISOR (6) can help the student set them. A student does not need to find a cure for cancer or bring life to mars to attain a good GRADE. Also see: SINE QUA NON (1).

\subsection{Elevator Pitch (๑)}

You are developing your research. You will be asked to explain it by many people, some of whom can affect your future, such as your defense jury. But friends and family will likewise want to be able to share with you your current pursuits. Some research is very esoteric, but it is still related to the rest of human knowledge. You must be able to communicate it in a language that is adjusted to the person who you are presenting the work to, and with just enough verbosity to explain what you are doing, without overwhelming your listener. Incidentally, that person includes yourself.

\footnotetext{
${ }^{5}$ Welcome to the problems of Scientific Ortodoxy.
} 
Therefore, learn how to quickly but thoroughly explain your research. Struggle to find its meaning and its impact on the world. Then learn how to present it to experts and non-experts alike, so that you are prepared to discuss it without much effort. You should be able to convey its relevance in a few sentences at most. And if your work seems too "theoretical," remember that even the most useful, common tools of mathematics, such as complex numbers, were once regarded as esoteric, useless knowledge ${ }^{6}$.

Rationale: The relevance of one's research is considerably affected by the impact it can have on their peers. It is important to create LASTING RESULTS (28), but verbally sharing the results is not just as far-reaching as publishing them in writing. Even more during the initial research stage, one should collaborate with its peers and belong to a WOLF PACK (19), as being able to communicate with anyone will require a deep, intricate understanding from the student, forcing them to expand their knowledge about the field. Also see: NO TELEPATHY Allowed (29).

\subsection{Safety Net (๑)}

Sometimes not everything goes according to plan. Some critical data didn't come through. Someone else published your idea right before you did. You lost all your test results ${ }^{7}$. The path you have placed all your bets on leads to an inconsistent mess. The complexity of what you were trying to tackle was underestimated. Those times may lead you to despair and, in some extreme situations, make you ponder on abandoning your research.

Therefore, hope for the best, but plan for the worst. Problems happen. While you can hope that this is not the case for you, it is better to be prepared for the not-so-good scenarios. Keep evaluating the risks of undertaking your dissertation, and draft a Plan B. What if the problem is too complex? What if the test results are not what you expected? What if the datasets are wrong? Talk to your colleagues and advisor and learn from their failure stories nobody ever gets good at what they do if they don't fail. Mitigate those risks as much as possible, and you might end up saving your thesis from an otherwise catastrophic event.

Rationale: As Murphy's law puts it, "anything that can go wrong, will go wrong". While it is impossible to predict the future, one can take the necessary measures to accommodate the risk. In fact, "risk management" is something that is often taught in some courses, and the student should be motivated to think beforehand about what might go wrong. Preparing for the most likely failure scenarios will largely reduce their possible impact, both in the TIME

\footnotetext{
6 "I am not for a moment suggesting that everything that goes on in laboratories will ultimately turn to some unexpected practical use or that an ultimate practical use is its actual justification. Much more am I pleading for the abolition of the word "use", and for the freeing of the human spirit. To be sure, we shall free some harmless cranks. To be sure, we shall thus waste some precious dollars. But what is infinitely more important is that we shall be striking the shackles off the human mind and setting it free for the adventures which in our own day have, on the one hand, taken Hale and Rutherford and Einstein and their peers millions upon millions of miles into the uttermost realms of space, and on the other, loosed the boundless energy imprisoned in the atom." [7]

${ }^{7}$ And somehow, you've managed to reach your graduation year without ever hearing about backups or version control systems.
}

it takes to complete the dissertation as in the overall work QUALITY, not to mention the psychological stability of the student. Also see: BEATEN TRACK (8), ADVISOR'S ADVICE (7).

\subsection{Big Picture (๑)}

You are being а воокwоrм (21), reading through many papers and books. There are infinitely many details in the material you are reviewing, and you are following the path of citations and related work - which brings even more literature to the table. You might even be attempting a systematic literature review, and your current search keywords result in thousands of scientific articles. You will never be able to read all of them, even if you dedicated your whole year to that. You need a better strategy to navigate through the state of the art and acquire meaningful insights for your research. You feel lost...

Therefore, seek insights, not details. Insights can be challenging to achieve, and it is common to feel lost in so many technical descriptions. But it is easier to derive details from the big picture than the opposite. Seek the key insights into what you are studying. Ask about the big ideas, and retain those! You can always go back for the details. Establish inclusion and exclusion criteria to help you skim through thousands of articles, and struggle to end up with the few dozens that are the most relevant.

Rationale: Learning the technicalities of a theory is essential to be able to apply it correctly, and that's why it is so common for degrees to focus on teaching specificities. But an approach to research does not share the same expectations, as the typical amount of knowledge available is overwhelming, and studying it all would not be possible in the TIME available for the work. Furthermore, researchers need to understand the state of the art of their research - to have all those necessary insights - but do not have to reproduce all the work from their peers, as it is expected for one to stand on the SHOULDERS OF GIANTS (11). As students progress on their work and become more focused on a small set of research questions, they can go back and search for the details. Also see: LANTERn TO LASER (10), SAFETY NET (14).

\subsection{Dissertation Ownership (๑)}

You are following your ADVISOR's ADVICE (7) and trust their plan for your dissertation. Your research might even be part of a larger project. But your advisor's time is (very) limited, and divided among several students. If you keep waiting for your advisor's feedback for every detail, every step, every small decision on your path, this interaction will quickly become a bottleneck, and your research will slow down to a crawl.

Therefore, struggle to assume the ownership of your dissertation. Do not be afraid to make decisions or mistakes. Your level of autonomy is a crucial factor in your evaluation. A discussion with your advisor about failed attempts to solve your problem will always be more relevant than asking for guidance every step of the way. On the other hand, not having any work to discuss will provide a very frustrating meeting for both you and your advisor. Be bold, be brave! And be open to redo stuff. Do not regard it as 
wasted time, though; it was an investment in your knowledge, so your next attempt turns out to be even better. Eventually, you will become the most knowledgeable person in your topic.

Rationale: A dissertation is much more than the document students deliver at the end of their program. That is the reason why so many thesis front pages contain the words "in partial fulfillment of the requirements for the degree of (...)". Part of the dissertation requires students to demonstrate autonomy at pursuing their research project. While the ADVISOR's ADVICE (7) can be of great help to make informed decisions, students must own their research and move forward, even in the eventual unavailability of their advisor, so that TIME requirements are successfully met. These expectations should always be made very clear from the beginning to avoid breaking unrealistic assumptions of each side's role. Also see: SELF-SUFFICIENT RESEARCH (4), POISONED SALARY (2), ELEVATOR PITCH (13), TOPIC PASSION (3).

\subsection{Point of no Return (o)}

You know beforehand the requirements for your program, as you have got acquainted with the SINE QUA NON (1), including its deadlines and required artifacts. Some goals might be flexible, but deadlines are mostly rigid. You need to have a realistic expectation of when you need to start working on things to ensure you can successfully complete them, as well as understand that at a certain point, there will not be enough time to substantial change your work.

Therefore, define your goals early and set a plan to achieve them on time. Mark critical points along your project and try to evaluate when you will be so compromised with your plan that you won't have time to change it. The same thing applies for your SAFETY NET (14); you should be keenly aware of when even the Plan $B$ becomes infeasible, to know precisely when to activate it. From that point on, resist making changes to your project, even if they seem attractive to you; and focus on achieving your goals.

Rationale: The most strict restriction of this phase of the degree is probably the delivery schedule. Novice researchers tend to be very receptive to new ideas that improve their work, particularly when they exhibit TOPIC PASSION (3) and start displaying a comfortable level of Dissertation OWNERSHip (16). Still some of these might increase the COMPLEXITY. At some point, those ideas might need to be postponed or pushed back to ensure the work can be finished within the defined TIME. Also see: SUStained EFFort (20), SOLVABLE PROBLEM (12).

\subsection{Uncomplicated Life (๑)}

You are about to begin what will probably be the most extended and most autonomous project you have ever worked. It might also be the first time you earn money and feel (more) financially independent. You might be tempted to rent an apartment or buy a house. You might be contacted by a prospective company that wants to hire you as soon as possible. Congratulations! This is good and perfectly natural. But any changes you introduce in your life during this phase will require a time investment from you, postponing the work on your dissertation.

Therefore, avoid complications in your life during your dissertation. Set realistic expectations. You can't control everything. Still, you might be able to postpone significant changes in your lifestyle, such as switching homes or accepting new projects. If you can stay focused on your project, you will yield better results, which will provide better support for kick-starting your professional career.

Rationale: Students doing research are typically reaching their adulthood and becoming fully independent. Most try to be financially independent during this period; others move in with their companions or decide to move to a better apartment. We often see students becoming overwhelmed by their professional and personal lives, impairing their final academic requirements, to the point of completely (and even indefinitely) postponing their dissertation so that they don't let down their employers, or so they can meet new financial obligations. This is a very tricky situation; on the one hand, it is ultimately the students' life and their free will to make such choices, no matter how much the advisor disagrees with them. On the other hand, experience dictates that it is a dangerous slippery slope on the very verge of completing their studies, which will ultimately open a broader and more relevant array of professional opportunities. Also see: POISONED SAlAry (2).

\subsection{Wolf Pack (๑)}

You are undergoing your dissertation on something that you clearly display a TOPIC PASSION (3) for. You have been a BOOKWORM (21), attempting to stand on the sHoulders of GIANTs (11). You feel overwhelmed by the amount of information, though, and finding a SOLVABLE PROBLEM (12) seems a daunting goal. You are filled with doubts. You need someone who knows the BEATEN TRACK (8).

Therefore, join a research group. Your colleagues might not be giants yet, but they can still make you taller. Discuss your work with them frequently. Help them with their own work. Find people with whom you can debate your ideas, who are working on the same field, who can provide valuable insights and constructive criticism on your project; but also someone with who you can laugh to renew your energies. Even basic things as having someone to cheer you up when you succeed, and support you when you fail can make a difference. After all, "when the snows fall and the white winds blow, the lone wolf dies, but the pack survives". ${ }^{8}$

Rationale: This all comes down to drinking from a source where people have been performing research in the same (or similar) topics as the student. This would foster shared knowledge and resources, easing the effort needed to achieve a SOLVABLE PROBLEM (12). On the other hand, academic research is not relevant if not shared with peers. The ELEvator PITCH (13) highlights the need to be able to clearly and thoroughly communicate the student's work. But such proficiency can only be obtained by much practice and discussion with peers. A research group would help to bootstrap this loop, training the students with a multitude of insights and questions that

\footnotetext{
${ }^{8}$ Quoting the late Lord Eddard Stark, head of House Stark.
} 
will incrementally prepare them. Also see: LASTING RESULTS (28), REWRITE LOOP (25), NO TELEPATHY ALLOWED (29).

\subsection{Sustained Effort (๑)}

You are engaged in your goals and deliverables, keenly aware of the POINT OF NO RETURN (17), but the road is long, hard, and full of distractions. You need to keep advancing towards your objective. Continuous progress isn't easy, and researchers seem to have a knack for procrastination. But small steps can be taken when large ones are elusive or unattractive.

Therefore, keep a sustained effort. Always make progress, even if it is minimal. Start doing something easy, and you may find yourself working hard on meaningful tasks. Gradually, your work efficiency will become much better, and your days more productive. Do not incur in heroic runs of ultra-productive sleepless weekends, only to be a wreck in the next week. Controlling your creativity is not easy, as many authors well know and tell. But you must realize that you are not pursuing your life's work; instead, you are undergoing a time-boxed trial. It's a marathon, not a series of sprints.

Rationale: Work efficiency is a trained skill. During the first weeks, the student might struggle to be efficient, as they become overwhelmed by the amount of new knowledge they need to absorb, and the DisSERTATION OWNERSHIP (16) they still lack. However, as with everything that requires practice, one will naturally become better if one keeps pushing through. Different people exhibit different responses to stress, though. Some students work very well under a deadline-driven development approach ${ }^{9}$, and most of their work tends to appear when TIME is running out. Others panic in the endgame and require more discipline, something that even the most brilliant researchers lack, as they tend to be distracted by the most useless pieces of trivia. In both cases, the resulting QUALITY might become a one-shot attempt; either it works, or there would be no TIME for improvements. Experience shows that those who keep doing small, incremental steps, are those that are best able to deal with higher COMPLEXITY, and ultimately achieve the best QUALITY and GRADE. Temet nosce. Also see: REWrite loop (25), BOOKWORM (21).

\subsection{Bookworm (0)}

Your degree is structured to teach you abstract concepts that you can reuse throughout your professional life. But your dissertation will be about a very concrete thing. You'll be asked to make a novel contribution. That originality will not be measured against your town or country, but against all human knowledge. The world, however, is vast, having many people. And you are just but one person, with barely enough time to attempt a tiny contribution.

Therefore, read, read, read! Do not assume nobody else ever thought about what you are working in. Read everything you can before committing to your research. Aim to know what everyone else did, and learn where they have failed. If you suddenly realize, perhaps with surprise, that at the end of the long journey that represented your education, you are now convict that "I know that

\footnotetext{
${ }^{9} \mathrm{We}$, the authors, shamelessly assume this trait.
}

I know nothing" was Plato describing your mood, then do not be afraid; you are on the right track. Read, and learn to stand on the SHOULDERS OF GIANTS (11).

Rationale: One might believe that a three or five-year degree has taught the pupil everything they need to become a professional. This is, however, misleading. The way university degrees are structured, particularly at undergraduate levels, aims at achieving a balance between teaching practical knowledge and the fundamentals that are needed for the student to cope with the advancement of said knowledge. In fact, there are many occurrences of a perceivable lag between what is taught and what the industry needs. This isn't necessarily bad, as the industry tends to follow cycles and hype much faster than academia, without much concern of scientific basis. However, the sudden shift of focus between wide-band information and the COMPLEXITY required to produce original work creates a significant gap of knowledge that must be filled. Being in a WOLF PACK (19) helps, as does having an INFORMED ADVISOR (6). But new scientific knowledge is published every day in hundreds of conferences and journals, so the required pace and focus to absorb new knowledge must come from the student's own will, TIME, and effort. Also see: TOPIC PASSION (3), LANTERN TO LASER (10), BIG PICTURE (15).

\subsection{Not about the Code (๑)}

You are developing your research, coding all day. Building code feels vital to you, but it is not. In science, we build things only to understand underlying principles and to advance the state of the art. Your hypothesis, problem, methodology, and results are all important; your code, not so much.

Therefore, don't spend more time focusing on your code than that which is needed to answer your research questions. The code is not the goal, but a conduit that allows you to learn. Tools are there to help, but the SOLVABLE PROBLEM (12) you are trying to solve is not how to build tools ${ }^{10}$. So keep the focus on what you are trying to accomplish and stop writing code as soon as you have the results you want, or you might reach a POINT OF NO RETURN (17). However, publishing the tool you created, as well as any data you used, is important if you want LASTING RESULTS (28) that can be easily reproduced by others; but it is still not the dissertation.

Rationale: Throughout their course, students are encouraged to create, and are graded according to, the code they write. This sense of purpose might be difficult to contradict. It is very important to make them understand, as soon as possible, that although the COMPLEXITY of their work might be correlated to the degree of complexity of their code, it is not the code itself that will validate their findings and grant them their GRADE. A good QUALITY dissertation might have no code at all, just as a bad quality one might involve lots of complex code. Developing code is often a task required for a dissertation in Computer Science, but even outside this context, other artifacts might be typical as well. The same concept

\footnotetext{
${ }^{10}$ Except if your dissertation's main hypothesis is precisely "how should one build this particular tool". Even so, we would argue that the answer is still not the code, but the algorithmic, architectural and design decisions that eventually addressed the intended desiderata.
} 
applies to accessory artifacts that complement the dissertation, but are not a goal per se. Also see: BIG PICTURE (15).

\subsection{Results are Results (๑)}

You are attempting to provide an answer to a problem. You believe you have sufficient evidence to believe your SOLVABLE PROBLEM (12) to be... solvable. But as your work unfolds, it turns out you are wrong. Most scientific research focuses on presenting good results and ignores the existence of failures. But there are many things to learn from them, particularly how to avoid repeating the same mistakes. If your research is framed in such a way that the main hypothesis is a yes/no answer, then you should be prepared to live with a resounding no.

Therefore, do not attempt to hide bad results, as they are results too. If your bad results made you take a different path along the way, write about it, so others do not make the same mistake. And even if it seems you have reached a dead-end, past the POINT OF NO RETURN (17), do not quit, and present your dissertation in a different light. By leveraging your failures as lessons learned, being FORWARD-LOOKING (30), and constructive, your dissertation might have success as negative findings are still a valuable component of the scientific literature [10]. In any case, be honest about it with your advisor, because what seems like a failure to you, might be something that they can easily leverage in a different perspective.

Rationale: One of the attributes of a dissertation with a high level of COMPLEXITY is its originality, i.e., something that no one has ever tried before. Although this sort of work usually undergoes a preliminary exploration phase to assess the plausibility of the hypothesis, there is always an inherent risk that it might just not end up working, or being simply wrong. And there might not be enough TIME left to correct the course, possibly due to an overlook of a SAFETY NET (14). Such is the nature of science; every so often good ideas turn out to be dead-ends, and sometimes discoveries are made by accident. Still, when a promising idea, in light of positive preliminary exploration, turns out to be wrong, that, per $s e$, is surprising; and the dissemination of such surprises may be welcomed by the community. Also see: ADVISOR's ADVICE (7), SAFE HOUSE (27), FORWARD-LOOKING (30).

\subsection{Self-Critic (o)}

Anything you write, be it an article or your thesis, will be reviewed by someone else, particularly if you want to attain LASTING REsults (28). Maybe the test population is biased. Perhaps there are confounding variables that you were not able to control. A framework already existed that you did not found during your literature review, c.f. SHOULDERS OF GIANTS (11). Or the benchmarks you have used are not representative of real-world scenarios. If you do not try to poke holes in your own work, you will not know how to defend yourself when others try to. In any case, a SOLVABLE PROBLEM (12) that cannot be falsifiable by any known mechanism is, by definition, unsolvable.

Therefore, be the first to criticize your own work. Finding problems early will allow you to write a better and more defensible dissertation. As Richard Feynman put it, "the first principle is that you must not fool yourself; and you are the easiest person to fool". So be honest with yourself while evaluating your work. Self-criticism keeps you grounded and drives you to improve through fair observation of your performance. However, overdosing on self-criticism can lead to an undesired impact on your self-esteem, causing unnecessary anxiety and depression. The key idea is to achieve a healthy balance, providing the basis for building your SAFE HOUSE (27) and be FORWARD-LOOKING (30).

Rationale: Most, if not all, topics outside pure mathematics rely on a contingent, usually statistical, evidence towards a certain belief. Proof, in this sense, is failing to falsify a falsifiable claim $^{11}$ after a broad and persistent attempt to do it. It is imperative that this continuous effort is made by the student, without which there can be no true DisSERTATION OWNERSHIP (16). Fast-forward all the epistemological consequences, and the rationale becomes simple: a student that does not attempt to refute their work will hardly ever recognize failure, with dire consequences to the validity of their research and the resulting GRADE. Also see: WOLF PACK (19), SAFE HOUSE (27).

\subsection{Rewrite Loop (๑)}

You are writing your dissertation. Writing is hard. Writing about technical topics is even harder. You will need to please your advisors, and they will ask for several rewrites of (at least) sections not clear to them. Writing the perfect sentence takes time; time that might be wasted if you have to scrap or rewrite that sentence later.

Therefore, rewrite often. Plan on rewriting your dissertation several times before it is accepted as finished. Do not expect, or attempt, to write it all in one swift stroke of the pen, as you will get stuck trying to find those perfect words in every single sentence. Instead, try writing whatever comes into your mind, and later be a SELF-READER (26) and a SELF-CRITIC (24) and improve the text incrementally.

Rationale: Students typically under-estimate the TIME they will need to write their thesis. And when they finally sit down to carefully write the first few pages of their masterpiece, they come to the hard realization that it takes much more TIME than they initially anticipated. This is typically due to a lack of confidence in their own writing; by self-doubting every word they write, they will get stuck often. Also, writing faster, even if not with an optimal QUALITY at first, will allow the student to better deal with the COMPLEXITY of the thesis as it will be easier to remember what was written before. Also see: NO TELEPATHY ALLOWED (29).

\subsection{Self-reader (o)}

You are writing your dissertation. Writing is hard. Writing about technical and scientific topics is harder. However, you have been trained to become an engineer, not a writer. Your dissertation is probably the first thing as close to a book you have ever attempted to do. Good writing is an art, but being a BоoкwORM (21) now helps

\footnotetext{
${ }^{11}$ Try to say "failing to falsify a falsifiable claim" five times in a row, and after that read about hypothesis testing and the null hypothesis.
} 
you recognize quality when you see it.

Therefore, print and read your own dissertation often. Do not just glance at the screen again and again, as it is tough to have a sense of the whole using current digital media. Print it, and, if possible, read it away from your workplace. Reading out loud works well for many students. Bring a red pen. Assume the posture of your own teacher: tell yourself what you do not like about it and then improve in a REWRITE LOOP (25). You do not have to read the whole thesis in one act. Break it into smaller pieces (e.g., chapters), and check if each piece makes sense on its own. Ask yourself what you intend to convey with each particular paragraph, and if it is adding new information to the reader. A dissertation is not a cata$\log$ of information, so be aware of breaks in the story thread; if the subject changes very quickly and the reason will only be apparent afterward, then the reader will become confused.

Rationale: The GRADE of the student is decided by a jury, and the primary contact they have with the student's work is through their document. A good QUALITY work will shine through a well-written dissertation and be dulled when not enough effort has been put into the later stages of the work. As the COMPLEXITY of the project increases alongside the document's length, it becomes harder and harder to maintain a mental picture of the overall state of the text. Particularly, after several cycles of the REWRITE LOOP (25), incorporating feedback from colleagues, reviewers, and advisors, the fluency of the document might become at risk. Therefore, leveraging the student's acquired habit of being a Bookworm (21), it is now essential for the student to read, and keep reading, their own writing. Also see: No telepathy Allowed (29).

\subsection{Safe House (o)}

You have finished your research work, and you are wrapping up your dissertation. During your project, you have found possible answers to your SOLVABLE PROBLEM (12), and you have attempted to validate them using a scientific methodology. Afterward, you have provided arguments that support your fundamental hypothesis. By being a SELF-CRITIC (24), you have realized that there might exist several counter-arguments that threaten your conclusions. Still, there is value in your work.

Therefore, establish the limits of truth of your conclusions (usually known as the scope) by being aware of the threats. Do not attempt to claim universal truth unless you have solid proof, which is unlikely outside the realm of mathematics. Hence, provide the foundations for successfully arguing why you do not think the belief is misguided by clearly defining your premises and your methodology, and showing how your conclusions follow from these. Then proceed to provide a constructive argument about why you do not think the threats you have identified are relevant (within your established boundaries), or if they actually are, how they can be tackled in the future, c.f. FORWARD-LOOKING (30). Having already attempted to achieve LASTING RESULTS (28) helps because it forces your work to go through external reviewers that usually point out existing pitfalls, even if your paper gets accepted for publication. Do not take these attacks personally. No research is ever complete, and science advances by questioning itself, not by blind trust on what others, even if they are authorities, have said ${ }^{12}$.

Rationale: Basic psychology dictates that the student may attempt to defend their work beyond reasonable evidence, which is, well... reasonable. But it is also expected for a jury to contradict the student's efforts, and these opposing forces establish the typical viva voce defense. Preemptive disclosure of threats contributes to the perception of QUALITY of the final work, and the way the student prepares itself to deal with questions and attacks from the jury is typically a fundamental evaluation point that influences the final GRADE. Also see: SELF-CRITIC (24), WOLF PACK (19).

\subsection{Lasting Results (๑)}

You have finished your research work, and you are wrapping up your dissertation. Research is only useful if it reaches a larger audience, and the primary mechanism for that is peer-reviewed publications. In many fields, your reputation is determined by what you publish. Your research might also be part of a bigger project that requires publishing. Publishing before defending your dissertation increases the odds of a good GRADE.

Therefore, write a paper with your contributions. Abstract one key part of your research into a paper, and attempt to publish it in a peer-reviewed conference or journal. Your advisor probably knows the best venue for your particular topic. If you intend to use this as an argument to increase your grade, you should attempt to plan this beforehand, so that the acceptance letter arrives before your public defense; be aware of any POINT OF NO RETURN (17). Also, make sure your results are reproducible, as this will allow others to create new work based on your research. This means that the data, materials, and methods used should all be public.

Rationale: Shorter papers have a higher probability of being read than longer dissertations. A good dissertation can possibly be broken down into multiple contributions, each of them proving interesting to different audiences. Peer-reviews, especially those conducted in reputable venues (such as high impact-factor journals and highlyranked conferences), are an adequate form of scientific acceptance that correlates with COMPLEXITY, QUALITY and originality, and as such impacts the final Grade. Also see: FORWARD-LOOKING (30).

\subsection{No Telepathy Allowed (๑)}

You are almost finishing your dissertation and investing in the REWRITE LOOP (25). However, you have been trained to become an engineer, not a writer. Your dissertation is probably the first thing as close to a book you have ever attempted to do. But (good) writing is an art. You are also writing for two target audiences. The first (and possibly the one you are most worried about), is the jury, as they will decide your grade. The second is a wider scientific audience, composed by both younger colleagues who will continue your topic, and strangers who will happen to find your LASTING RESUlts (28) available on the Internet. The former might find you more accessible than the latter.

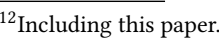


Therefore, be explicit about your ideas. No matter if the readers are your evaluation jury, younger colleagues, or fellow researchers, the fact is that your dissertation - the actual document - will be the primary vehicle of your work, and readers will not have you around to explain it to them. Make sure people understand not only what you have written but why it matters. Do not be eager just to display the results, and fail to convey how you managed to reach them. There is always a lot of information lying in your - and your advisor's - mind, which should be explicitly detailed in your dissertation. Do not ever assume that your reader knows what you are talking about, so make sure that you use references that point to further reading material.

Rationale: When someone dedicates too much TIME to a certain topic, it becomes hard for them to determine what is common knowledge and what are facts only experts in the topic know about. Good QUALITY work must be able to circumvent this problem which is further exacerbated in a dissertation with a higher level of COMPLEXITY. It is also common for authors to forget writing about the path they walked towards their final results - mainly due to the common top-down approach to writing. Not knowing about failed experiments can make readers have difficulty in understanding choices taken during the journey, as sometimes the devil is in the unwritten details. Also see: WOlf PACK (19), RESUlts ARE RESULTS (23), SELF-READER (26).

\subsection{Forward-looking (o)}

You are wrapping up your research and polishing your document. It is now your turn to be the SHOULDERS OF GIANTS (11) for someone else. Your dissertation is your creation, and you will want it to flourish by contributing to LASTING RESULTS (28). But, every idea you did not have time to explore, every alternative you dismissed, can be avenues that others might pursue as to perpetuate your work.

Therefore, see beyond your creation. Imagine yourself with two more years of free time, or having started all over, or with a team of three people. What could you do beyond incremental improvement? Sum up your these conclusions as a "future work" section, which would help others understand how they can take your hard pursuit and push it just a little bit further. There is nothing as satisfying as knowing your work was not lost in the corner of an old library.

Rationale: Leaving things to be done is not necessarily a signal of lack of QUALITY, but rather that the immutable constraint of TIME prevents the exploration of every possible branch deriving from the COMPLEXITY of your work. This must be differentiated from the absence of proper planning, over-eagerness, or lack of commitment. On the other hand, the presentation of research without a foreseeable future can easily convey the perception of an unoriginal, simplistic, or irrelevant work. Also see: RESUlts ARE RESUlts (23), NO TELEPATHY ALLOWED (29).

\section{CONCLUSION}

We started by claiming that both the academic machinery and human psychology evidence behavioral patterns that are highly correlated with the success of producing and defending a master's thesis.

From this observation, this work described a pattern language for the M.Sc. student comprised of thirty (30) interrelated patterns in the spirit of Alexander et al. [1, 2]. As these patterns are far from being complete - in the usual sense - we decided to first identify and capture them as "patlets" of problem-solution pairs.

Although this paper was written thinking on the prospective student as its reader, it is also meant to target their advisors - both as a way of acquiring insight into the students' process, as well as hoping they would serve as a conduit to raise awareness among their pupil.

As it is out of the scope of this paper to provide empirical evidence beyond our observations, categorization, and generalization from others' work, we intend in the future to measure the relevance of these patterns resorting to observational methods before, during, and after their dissertation work. Such an endeavor will undoubtedly provide us a new stream of patterns that can be incorporated in the present language.

\section{ACKNOWLEDGEMENTS}

We would like to thank Takashi Iba from Keio University, Japan, for his collaboration during the shepherding phase, providing invaluable feedback for this paper, as well as the attendees of our Writers' Workshop at EuroPLoP 2019.

\section{REFERENCES}

[1] Christopher Alexander. 1999. The Origins of Pattern Theory: The Future of the Theory, and the Generation of a Living World. IEEE Software 16, 5 (1999), 71-82. https://doi.org/10.1109/52.795104

[2] Christopher Alexander, Sara Ishikawa, Murray Silverstein, Max Jacobson, Ingrid Fiksdahl-King, and Shlomo Angel. 1977. A Pattern Language - Towns, Buildings, Construction. Oxford University Press.

[3] Laura LB Barnes, Menna O Agago, and William T Coombs. 1998. Effects of job-related stress on faculty intention to leave academia. Research in higher education 39, 4 (1998), 457-469.

[4] Joseph Bergin. 2002. Patterns for the Doctoral Student. https://csis.pace.edu/ $\sim$ bergin/patterns/DoctoralPatterns.html

[5] Pauline Rose Clance. 1985. The impostor phenomenon: Overcoming the fear that haunts your success. Peachtree Pub Ltd.

[6] Catherine Cozzarelli and Brenda Major. 1990. Exploring the validity of the impostor phenomenon. Journal of social and clinical psychology 9, 4 (1990), 401-417.

[7] Abraham Flexner. 1939. The usefulness of useless knowledge. Harpers (1939), 544-552.

[8] Paul Gruba and Justin Zobel. 2017. How To Write Your First Thesis (1st ed.). Springer Publishing Company, Incorporated.

[9] Justin Kruger and David Dunning. 1999. Unskilled and unaware of it: how difficulties in recognizing one's own incompetence lead to inflated self-assessments. Journal of personality and social psychology 77, 6 (1999), 1121.

[10] Natalie Matosin, Elisabeth Frank, Martin Engel, Jeremy S Lum, and Kelly A Newell. 2014. Negativity towards negative results: a discussion of the disconnect between scientific worth and scientific culture.

[11] Matt Might. 2010. The illustrated guide to a Ph. D. (2010).

[12] Justin Zobel. 2015. Writing for Computer Science (3rd ed.). Springer Publishing Company, Incorporated. 